\title{
PRINCESA BRAMBILLA - IMAGENS/TEXTO
}

\author{
Maria Aparecida Barbosa* \\ Universidade Federal de Santa Catarina
}

\begin{abstract}
Resumo: Ler o texto literário ilustrado é pensar simultaneamente imagens e palavras. Essa articulação entre o texto escrito e as ilustrações gera potencialidades, se amplia e se torna complexa. Coincide com discussões pertinentes sobre "o contemporâneo" de Giorgio Agamben, que ao somar àquilo que adere ao seu tempo o deslocamento e o distanciamento necessários para a compreensão desse, abala noções lineares da cronologia histórica. De certo modo a coincidência está relacionada com o atual interesse pelo conceito de "Nachleben" (sobrevivência), que pressupõe o resgate de imagens do passado, postulado pelo historiador de arte Aby Warburg em pesquisas sobre características de movimento da arte antiga nas imagens renascentistas de Botticelli. Para a tradução da novella Princesa Brambilla - um capriccio segundo Jakob Callot, de E. T. A. Hoffmann, com 8 gravuras cunhadas a partir de moldes originais de Callot (1820) ao português tais discussões foram fundamentais, como tento apresentar neste artigo. Palavras-chave: Tradução poética. Ilustração. Escrita/imagem.
\end{abstract}

\footnotetext{
* Possui graduação em Comunicação Social/jornalismo pela Universidade Federal de Minas Gerais (1987). Tem mestrado e doutorado pela Universidade Federal de Santa Catarina. É professora associada do Curso de Letras - Alemão do Departamento de Língua e Literatura Estrangeiras da Universidade Federal de Santa Catarina. Em 2012 completou o pós-doutorado sobre Modernismo e Movimentos de Vanguarda, na Westfälische Wilhems-Universität Münster. Florianópolis, Santa Catarina, Brasil. mail: aparecidabarbosaheidermann@gmail.com
} 


\title{
PRINCESS BRAMBILLA - IMAGES/TEXT
}

\begin{abstract}
Read the illustrated literary text is simultaneously think pictures and words. This articulation between the written text and pictures adds potential, expands and becomes complex. Coincides with nowadays discussions on Giorgio Agamben's «contemporary» that add to what adheres to respectively time the displacement and the distance needed to understand it, shakes linear notions of historical chronology. Somehow the coincidence is related to the current interest in the concept of «Nachleben" (survival), which assumes the images of the past ransom, postulated by the art historian Aby Warburg in a research on ancient art of motion characteristics in Renaissance pictures Botticelli's. For the translation of the Princesa Brambilla - um capriccio segundo Jakob Callot, de E. T. A. Hoffmann, com 8 gravuras cunhadas a partir de moldes originais de Callot (1820) to Portuguese such discussions were fundamental, as I try to present in this article.
\end{abstract}

Keywords: Poetic translation. Illustration. Writing/Picture.

Ler o texto literário ilustrado é pensar simultaneamente imagens e palavras. Essa articulação entre o texto escrito e as ilustrações gera potencialidades, se amplia e se torna complexa. Coincide com discussões pertinentes sobre "o contemporâneo" de Giorgio Agamben, que ao somar àquilo que adere ao seu tempo o deslocamento e o distanciamento necessários para a compreensão desse, abala noções lineares da cronologia histórica. De certo modo a coincidência está relacionada com o atual interesse pelo conceito de "Nachleben" (sobrevivência), que recupera imagens do passado, postulado pelo historiador de arte Aby Warburg em pesquisas sobre características de movimento da arte antiga nas imagens renascentistas de Botticelli.

O movimento dos cabelos e trajes esvoaçantes nas imagens "Nascimento da Vênus" (1485) e "Sagração da Primavera" (1482), de Sandro Botticelli, Warburg vê como expressões do interesse dos artistas do Quatrocentto italiano pela arte da Antiguidade, sobretudo neste caso, pelos Hinos de Homero - o texto manuscrito foi impresso em 1488 em Florença, cujo teor, porém, Warburg supõe já seria de conhecimento dos eruditos humanistas daquela época. Nas comparações refere igualmente às inscrições em alto-relevo feitas 
por Augustino de Duccio - “Alegoria” - para a Capela de São Sigismundo no Templo Malatestiano de Rímini, feitas sob orientação do arquiteto Leon Battista Alberti. A provável e mais próxima inspiração para Botticelli teria sido o poema Stanze per la Giosta (1475-78) de Angelo Policiano, no qual o preceptor da influente família florentina, os Médici, celebra seus mecenas. A hipótese de Warburg advém do fato de que tanto o poeta como o pintor teriam cometido as mesmas divergências quanto ao segundo hino à Afrodite, de Homero (WARBURG, 1893. p. 1-367).

Para a tradução da novela Princesa Brambilla - um capriccio segundo Jakob Callot, de E. T. A. Hoffmann com 8 gravuras cunhadas a partir de moldes originais de Callot $^{1,2}$ (1820) ao português tais discussões foram fundamentais, como tentarei apresentar neste artigo. Como se depreende pelo subtítulo, o escritor se inspirou nas litogravuras do gravador francês Jacques Callot (NANCY, 1592-1635).

Callot criou muitas imagens de batalhas; viveu na época de Luís XIII, quando o Cardeal Richelieu, chefe das questões de Estado introduziu com violência o poder centralizado na França. Contase que era ousado na vida, semelhante aos seus sólidos desenhos, pois quando Richelieu lhe pediu para registrar a tomada de Nancy, sua cidade natal, ele se negou dizendo que antes cortaria o dedo a eternizar com sua arte a humilhação dos nobres e da pátria (HOFFMANN, 2006). Mas, é importante destacar que Callot viveu anos na Itália como um andarilho e registrou com pitadas de humor e um realismo grotesco as personagens nômades: os ciganos das estradas, os artistas da commedia dell'arte nas praças urbanas

São esses os trabalhos que inspiram o escritor E. T. A. Hoffmann (1776-1822) a escrever a coletânea Quadros Fantásticos à maneira de Callot - do diário de um viajante entusiasta ${ }^{3}$, de 1814, o romance Elixires do Diabo - documentos póstumos do capuchinho Irmão Medardo editados pelo autor de Quadros Fantásticos à maneira de Callot, inúmeras intertextualidades sutis ao longo dos dois romances - Reflexões do Gato Murr e Os Elixires do Diabo - e dos 80 contos.

Introduzindo o breve texto "Jaques Callot", Hoffmann faz uma confissão do programa estético-literário que propunha desenvol- 
ver, qual seja apostar na riqueza de detalhes e na profundidade de campo, zona de nitidez atrás e à frente de uma cena, características das ilustrações do mestre francês. Ele se propõe a escrever à maneira dos desenhos:

Um poeta ou escritor, a quem se apresentassem em seu espírito romântico figurações da vida comum, e que as representasse agora, esplêndidas como na fonte, num estilo estranho e raro, não poderia tal poeta ou escritor se desculpar com o mestre, dizendo que quis trabalhar à maneira de Callot? (HOFFMANN, 2006)

A 24 de janeiro de 1820, no seu aniversário de 44 anos, o escritor Hoffmann recebera como presente do amigo médico Johann Ferdinand Koreff a série de Callot Balli di Sfessania (baile dos malucos). Essa série, do ano de 1622, contém 24 águas-fortes gravadas em cobre, representando pares de figuras ora conversando, ora tocando bandolim ou pandeiro, em poses grotescas e cômicas de duelo com espadas, cenas em primeiro plano de desafios hostis ou declarações amorosas, nas quais os protagonistas se fantasiam com narizes aduncos, óculos imensos, vestem exuberantes trajes carnavalescos ou teatrais e portam vistosos chapéus enfeitados com longos penachos.

O escritor alemão escolheu oito litografias para compor a novela Princesa Brambilla de oito capítulos, respectivamente duas por capítulo ímpar, e coube ao gravador Carl Friedrich Thiele prepará -las para a primeira edição. Diferentemente dos modelos de Callot, as imagens empregadas no livro de 1821 vinham sem títulos ou pano de fundo, soltas dentro das molduras. A omissão do contexto se mantém em edições mais recentes, como a da Insel, de 1967.

Por um lado, isso aumenta o efeito de leveza das ilustrações, principalmente das intermediárias, a terceira, a quarta e a quinta, que estão nas pontas dos pés e mal tocam o solo (KREMER, 2010. p. 238). As primeiras e as últimas figuras apoiam firmemente os pés no solo em atitude serena e graciosa; funcionam como moldura 
para o movimento explícito dos quadros intermediários. O todo corresponde ao ritmo da dramaturgia dentro da narrativa. As gravuras de Thiele, sem panos-de-fundo, não somente funcionariam como ilustração, mas espelham e reforçam os efeitos estéticos do texto escrito, permitindo a evocação e o reconhecimento recíproco entre o texto escrito e a imagem.

Por outro lado, destacados do fundo abstrato, os pares de figuras ainda mereceriam o elogio que Hoffmann fez a Callot, justamente dirigido aos elementos heterogêneos que "adquirem vida, se movimentam do remoto pano de fundo, a princípio quase irreconhecíveis, depois se aproximam e saltam brilhando nítidos e naturais para o primeiro plano"? (HOFFMANN, 2006)

Algumas dentre as 16 imagens de Callot preteridas por Hoffmann quando da composição mostram o arlequim indecoroso exibindo em poses licenciosas o bem-dotado pênis ou fazendo gestos obscenos. Tamanho atrevimento provavelmente não convinha figurar numa publicação do período romântico, mesmo se tratando de Hoffmann, um feroz crítico das convenções dos filisteus (burguesas).

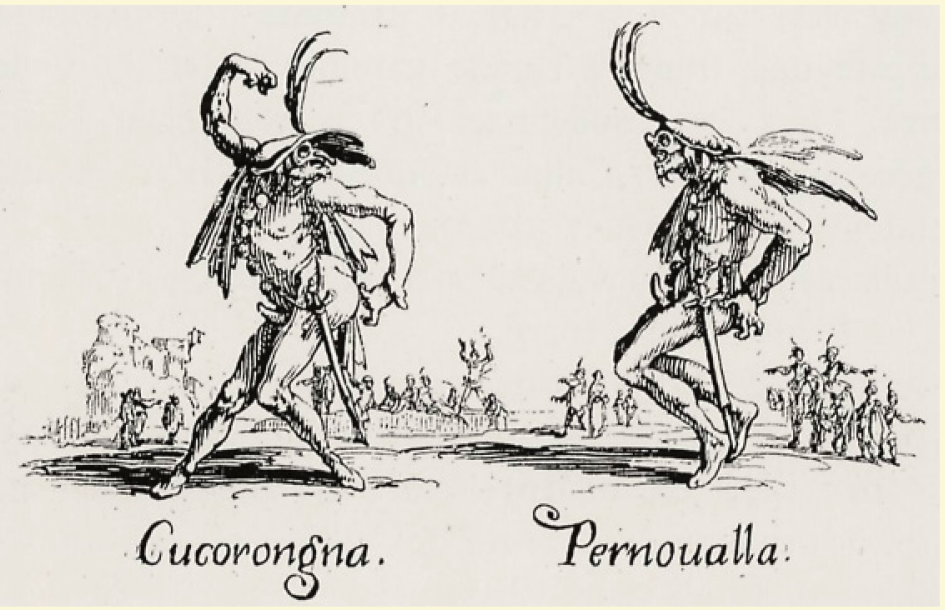

Figura 1: Balli di Sfessania, de Jacques Callot (Imagem em domínio público). ${ }^{4}$ 
No Prefácio da novela Princesa Brambilla, o narrador adverte:

\begin{abstract}
Princesa Brambilla não é um livro para pessoas inclinadas a levar tudo a sério e ao pé da letra. Mas, o prezado leitor desejoso e pronto a deixar de lado por algumas horas a seriedade e a abandonar-se ao atrevido e caprichoso jogo de um espírito alucinante, que talvez vez ou outra possa levar longe demais a impudência, o editor pede humildemente, que não perca de vista a base de toda a obra, vale lembrar as fantásticas caricaturas de Callot, e imagine tudo aquilo que um músico, por exemplo, poderia esperar de um capriccio ${ }^{5}$. E se o editor ousa lembrar o pensamento de Carlo Gozzi (no prefácio de 'Zeim, rei dos gênios') segundo o qual todo um arsenal de estrambelhos e aparições fantasmagóricas não é suficiente para dar alma a um conto, coisa que só pode lograr graças a um alicerce profundo, graças a uma idéia geral constituída sobre uma concepção filosófica da existência, o faz somente para aludir ao quanto ele intentava, não necessariamente ao que conseguiu fazer (HOFFMANN, no prelo).
\end{abstract}

A novela Princesa Brambilla trata do ator de comédias Giglio e da costureira de fantasias, Giacinta Soardi na cidade de Roma durante o carnaval. No momento em que a agulha fere o dedo da costureira, entretida no coser, inicia-se a fábula com acontecimentos estranhos que intervêm e perturbam o romance dos amantes. Uma princesa se instala no Palácio de Pistoia com um extravagante séquito e altera os modos e o comportamento do jovem ator - "romance ambulante, uma intriga sobre duas pernas" (HOFFMANN, no prelo) - que toda a cidade passa a considerar maluco. Por sua vez, a enciumada Giacinta parece apaixonada por um príncipe assírio que a vem cortejando em pleno Corso nas noites de carnaval. A narrativa ora dá a impressão de que o casal está representando papéis protagonistas de innamorati numa peça de teatro, ora sugere que forças mágicas e malignas intervêm drasticamente em suas vidas de Arlequim e Colombina. As imagens do Balli di Sfessania 
constituem um fio da meada que estrutura a narrativa, sendo que a máscara permite a brincadeira, é o artefato que permite a evasão da coincidência consigo mesmo.

Giglio resolveu se trajar com um belo par de calças de seda azul celeste, enfeitadas com laços vermelhos, combinando com as meias cor-de-rosa e sapatos brancos de cadarços vermelhos, o que compunha um bonito efeito, embora contrastasse muito singularmente com o resto da indumentária. (...) Reparou então um sujeito que, por sua figura engraçada, ultrapassava tudo que ele jamais vira do gênero. A máscara com barba pontiaguda, os óculos, os cabelos esticados, a postura do corpo, pendendo adiante com uma corcunda nas costas, o pé direito avançado - tudo indicava um Pantaleão, mas com tudo isso estava em desacordo o chapéu adornado com duas penas de galo afinadas na ponta. $\mathrm{O}$ corpete, as calças e a espada eram evidências claras da digna máscara Polichinelo (HOFFMANN, no prelo).

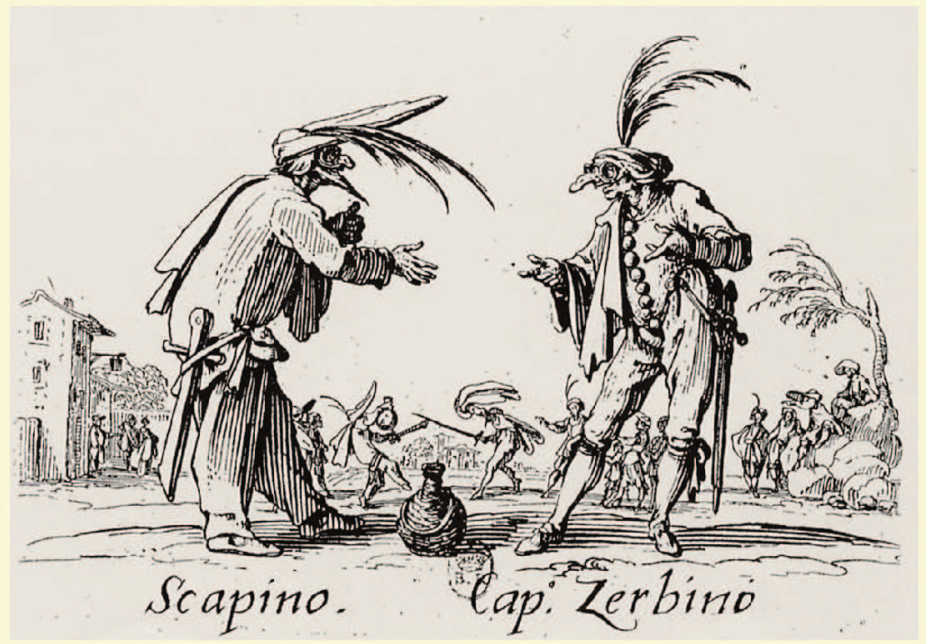

Figura 2: Balli di Sfessania, de Jacques Callot (Imagem em domínio público) ${ }_{.}{ }^{6}$ 
A irreverência do personagem Giglio é uma alegria alucinada e irônica. Por seu intermédio, Hoffmann participa de uma discussão sobre o teatro que tivera lugar na Itália, sobretudo em Veneza por volta de 1760 , e, ao fazê-lo, admite a orientação estética de sua literatura. Ele elogia o fantástico do Conde Carlo Gozzi ${ }^{7}$, autor que admirava e inseriu na novela na forma do personagem contador de histórias Príncipe Bastianello de Pistoia "semeia sementes de laranja no Corso e toma as máscaras sob sua proteção", o mesmo que finalmente se reporta à agulha que urde o enredo, um efeito de metonímia poética (Hoffmann: no prelo) ${ }^{8}$. Nesse livro, Hoffmann ironiza dois arquiinimigos do dramaturgo veneziano: o teatro trágico de Pietro Chiari (1712-1785) - parodiado na novela pelo pedante personagem diretor teatral, o Abade Antonio Chiari - e a reforma da commedia dell'arte iniciada por Carlo Goldoni (1707-1793) que transformara as arlequinadas bufas em comédia de costumes (à moda de Moliére) com influências do Esclarecimento.

Além de conduzir dessa maneira a opção pelo fantástico, a commedia dell'arte italiana contribui (como intertexto) na novela Princesa Brambilla com outros recursos. As máscaras (fantasias de carnaval) disfarçam as personagens e graças a seu mistério ampliam a possibilidade da ambiguidade e do nascimento seriado de "duplos". As personagens teatrais das fiabe (fábulas) de Gozzi dão suporte às metamorfoses. Para tanto auxiliam os recursos espaciais/cenários em Roma com a alternância entre o palco improvisado ao lado do Corso onde acontece o desfile carnavalesco e o Teatro Argentina palco (que de fato existiu) das peças trágicas de Chiari; ou entre o quartinho de costura de Giacinta e o Palácio di Pistoia, residência da princesa.

A ação poético-dramática deriva das ilustrações do teatro de rua feitas por $\mathrm{Callot}^{8}$, ou seja, do realismo grotesco e do riso universal que Bakhtin estudou na pesquisa sobre a Idade Média e Renascimento. Todavia, as personagens não fazem uso de falas escatológicas com ingredientes do carnaval medieval, tampouco exibem a descompostura de algumas imagens preteridas do Balli di Sfessania. Antes, as litografias selecionadas, por exemplo a terceira delas, que segue abaixo, se assemelham aos 


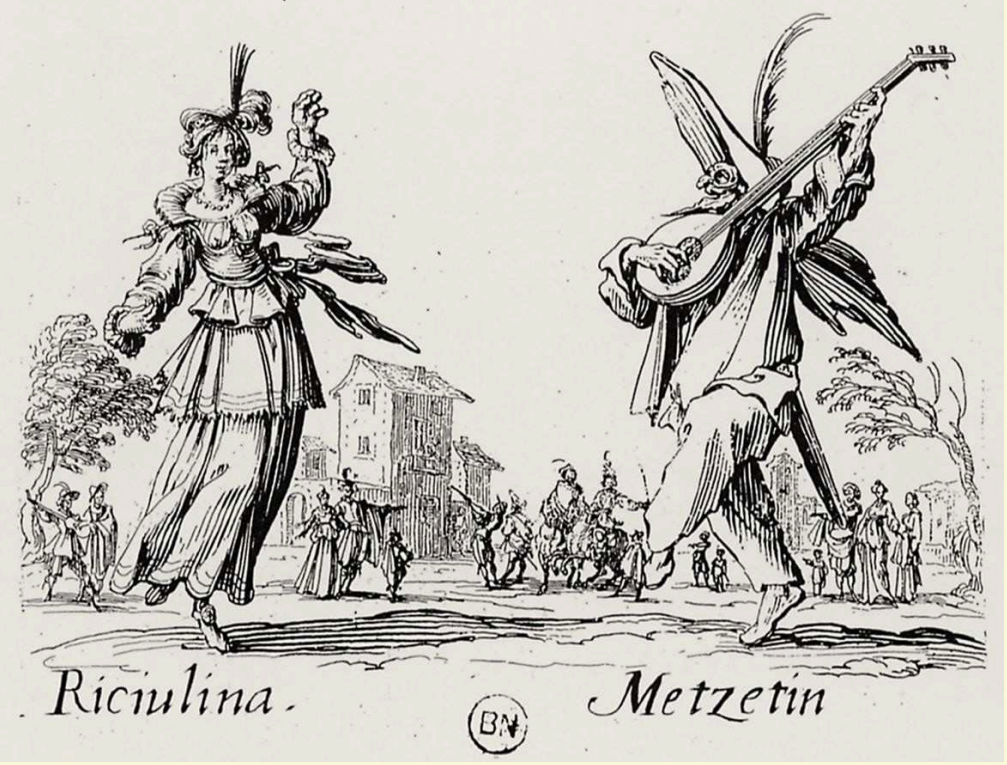

Figura 3: Balli di Sfessania, de Jacques Callot (Imagem em domínio público). ${ }^{10}$

desenhos para figurinos da comédia de intermezzo "La Peregrina", criados por Bernardo Buontalenti (1536-1608). Pelos figurinos de Buontalenti se interessou Aby Warburg num ensaio de 1895, no qual empreende uma leitura da história da arte acrescentando novos contextos e interações disciplinares, recorrendo para isso aos jornais da época Il diari del Pavoni, del Cavallino e del Benacci de maio de 1589, quando o Grão-Duque de Toscana Ferdinando I de Médice, após renunciar aos votos de cardeal, desposa Cristina di Lorena e encomenda no ensejo da celebração de bodas com a princesa francesa uma variedade de encenações teatrais, o que consistiu em rico levantamento teatral do ano, e foi bem documentado em livros e ilustrações. Tanto nos figurinos de Buontalenti, como nos madrigais musicais que acompanhavam essas encenações de Giovanni de' Bardi, Warburg reconhece indicações de modelos de escritores e artistas da Antiguidade. 


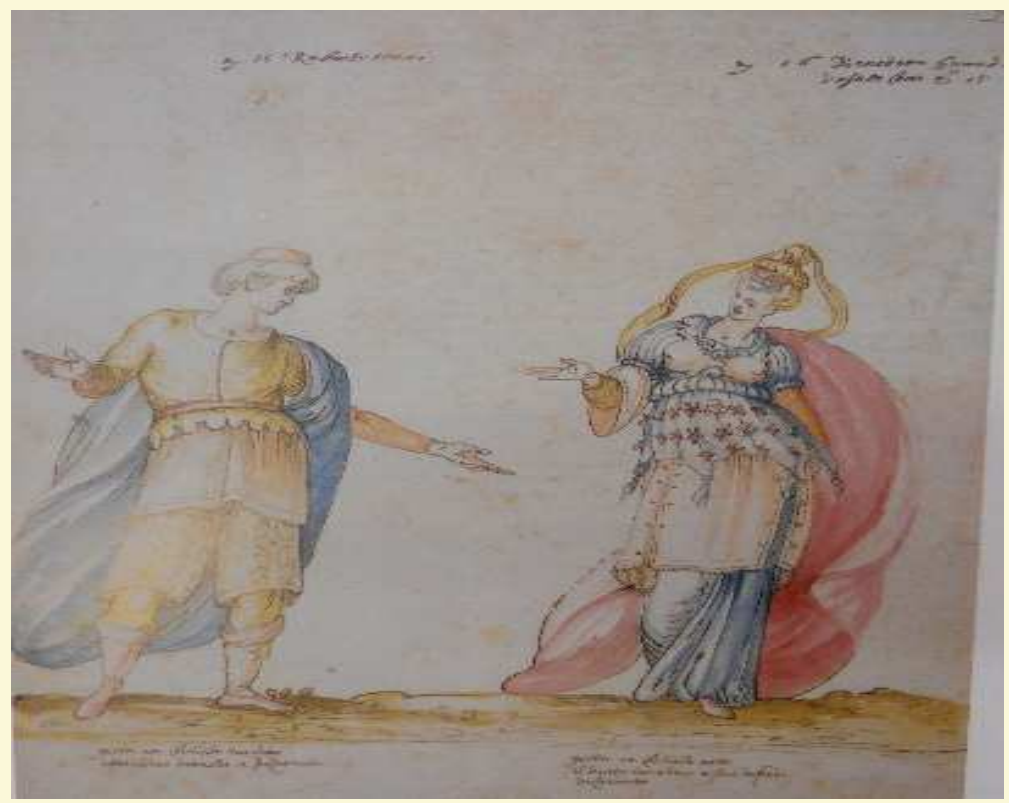

Figura 4: Costumes de Buontalenti para La Pellegrina, 1592 (imagem em domínio público). ${ }^{11}$

Notas

1. Prinzessin Brambilla - ein capriccio nach Jakob Callot, von E. T. A. Hoffmann, mit 8 Kupfern nach Callotschen Originalblättern.

2. Os estudos literários na Alemanha mantiveram-se céticos em relação à Princesa Brambilla até meados dos anos 60 do século $\mathrm{XX}$, pois só a liam como "arbitrariedade informe (...). Entrementes, ao contrário, o capriccio é reconhecido como singular obra em prosa, pioneira da literatura moderna do século XX, dentre outras devido à sua representação proto-surrealista do diferente em simultaneidade 
prismática, uma autorreflexão consciente da materialidade e da mídia, voltada à ilusão da realidade, o que remete a Kafka" (KREMER, 2010. P. 237)

3. Fantasiestücke in Callots Manier - Blätter aus dem Tagebuch eines reisenden Enthusiasten.

4. Disponível em: <http://www.zeno.org/Kunstwerke/A/Callot, +Jacques > . Acesso em: 18 de Julho de 2015.

5. Capriccio é um termo que designa um esboço de composição musical.

6. Disponível em: <http://www.zeno.org/Kunstwerke/A/Callot, + Jacques > . Acesso em: 18 de Julho de 2015.

7. Gozzi buscava a revitalização do teatro através de elementos mágicos. Escreveu dez "fiabe" (fábulas), sendo em prosa a fiaba "O Amor de Três Laranjas", de 1761. As outras foram compostas em versos; O corvo - em cinco atos, de 1762; O Rei Cervo em três atos, de 1762; Turandot - fábula tragicômica em cinco atos, de 1762; Dona Serpente, de 1762; Zobeide, de 1763; os mendigos sortudos, de 1764; o monstro azul em cinco atos, de 1764; o bonito passarinho verde, o abade filósofo em cinco atos, e Zeïm, rei dos gênios, de 1765. Outro texto muito reconhecido é o drama "as drogas do amor", de 1776. O dramaturgo deixou registradas curiosas confissões no livro "memórias inúteis da vida de Carlo Gozzi - escritas por ele mesmo e por ele mesmo com humildade publicadas". A partir de "Donna Serpente" Richard Wagner compôs (sua primeira ópera) "Donna Anna"; Puccini transformou "Turandot" em ópera. Nas versões de Wagner e Puccini, porém, o texto gozziano perdeu bastante do aspecto burlesco e cômico.

8. A criação da novela é atribuída a esse personagem velho, além disso, porque enquanto folheava as páginas do livrão e contava a história, era acompanhado pelas belas vozes barítonas dos ouvintes, com sons onomatopéicos conferindo o nome à história: Bram - bure - bil - bal - Ala... (HOFFMANN, no prelo, 2013).

9. Ao mostrar que a poesia se desenvolve no tempo e a pintura no espaço, Lessing põe por terra a equivalência das duas artes que se mantivera por séculos como indiscutível através do ut pictura poiesis, de Horácio. Mas ele alerta contra o pernicioso risco de se introduzir "na poesia a mania da descrição e na pintura o alegorismo", pois não vê as atribuições das formas artísticas dessa maneira estática: a descrição ele considera função da pintura e, na poesia, postula que a 
descrição se transforme em ação. As reflexões estão no ensaio "Laocoonte ou sobre as fronteiras da Pintura e da Poesia" com esclarecimentos ocasionais sobre diferentes pontos da história da arte antiga. Introdução, tradução e notas Márcio Seligmann-Silva. São Paulo: Iluminuras, 2012. O trecho literário clássico sobre o episódio do grupo Laocoonte e os dois filhos encontra-se na Ilíada, de Homero, e também na Eneida, de Virgílio: Laocoonte tentou evitar a entrada do cavalo de madeira na cidade de Troia, atirando um dardo contra o presente dos gregos. Os troianos consideraram um sinal dos deuses para aceitarem o presente, o fato de duas serpentes vindas do mar se aproximarem dos filhos de Laocoonte e envolvê-los, que acreditaram ser a vingança de Poseidon, rei das águas e protetor dos guerreiros invasores gregos. O pai grita por socorro, mas agoniza juntamente com os filhos. No ensaio Lessing refere-se à Ilíada e à escultura do grupo, uma das mais famosas esculturas da Antiguidade.

10. Disponível em: <http://www.zeno.org/Kunstwerke/A/Callot, +Jacques > . Acesso em: 18 de Julho de 2015.

11. Disponível em: < http://jeannedepompadour.blogspot.com.br/2012/04/costumes-by-inigo-jones-and-bernardo.html > . Acesso em: 20 de Julho de 2015.

\section{Referências}

AGAMBEN. Giorgio. O que é o contemporâneo? e outros ensaios. Trad. Vinícius Nicastro Honesko. Apresentação de VNH e Susana Scramin. Chapecó: Argos, 2009.

HOFFMANN, E. T. A. Princesa Brambilla. Trad.MAB. No prelo. . "Jacques Callot”. Trad. MAB. Revista Zunái online, 2006.

KREMER, Detlef. E. T. A. Hoffmann - Leben, Werke, Wirkung. Berlin/Ney York: Gruyter, 2010. 
WARBURG, Aby. "Sandro Botticellis 'Geburt der Venus'und 'Frühling' eine Untersuchung über die Vorstellungen von der Antike in der italienischen Renaissance". In: A. Warburg/Gesammelte Schriften. Leipzig, Berlin: B. G. Teubner, 1932. Volume I. P. 1-60.

. "I costumi teatrali per gli intermezzi del 1589 - i designi di Bernardo Buontalenti e il libro di Conti di Emilio de Cavalieri" (1895). In: A. Warburg/ Gesammelte Schriften. Leipzig, Berlin: B. G. Teubner, 1932. Volume I. P. 259300.

Recebido em: 19/07/2015

Aceito em: 02/09/2015 